\title{
QUANTITATIVE DETERMINATION OF DIHYDROSTREPTOMYCIN BY PERIODATE OXIDATION ${ }^{2}$
}

\author{
By EDWARD A. GARLOCK, JR., AND DONALD C. GROVE \\ (From the Federal Security Agency, Food and Drug Administration, Washington, D. C.)
}

Dihydrostreptomycin is produced commercially by the catalytic hydrogenation of streptomycin. The reaction involves the reduction of the aldehyde group in the streptose moiety of the streptomycin molecule to the corresponding primary carbinol group as evidenced by the failure of dihydrostreptomycin to react with carbonyl reagents or with alkali to produce maltol. As there are no chemical methods available for the direct determination of dihydrostreptomycin, it was desirable to investigate the development of such a method. A satisfactory procedure has been found and is based upon the measurement of formaldehyde liberated by the periodate oxidation of dihydrostreptomycin.

Periodate oxidation is a general method of cleaving the linkage between two adjacent hydroxyl bearing carbon atoms. If one of the hydroxyl groups is a primary carbinol, formaldehyde will be a reaction product (1). In the elucidation of the structure of streptomycin, it has been proven there is no primary carbinol group which will give rise to formaldehyde on treatment with periodate $(2,3)$. However, in the case of dihydrostreptomycin there is a primary carbinol adjacent to an hydroxyl, and formaldehyde is liberated by periodate oxidation. This has been observed experimentally by Lemieux, DeWalt and Wolfrom (4). These workers showed that dihydrostreptomycin when oxidized with 1.5 mole of periodate yielded 0.5 mole of formaldehyde while streptomycin yielded no formaldehyde. Fried and Stavely (5) have also found that the action of periodic acid on streptomycin $B$ and on dihydrostreptomycin B produces zero and one mole of formaldehyde, respectively.

Sodium metaperiodate was found to be the most suitable reagent for the oxidation of dihydrostreptomycin. Although the action of the salt

\footnotetext{
1 Presented at the Second National Symposium on Recent Advances in Antibiotics Research held in Washington, D. C., April 11-12, 1949, under the auspices of the Antibiotics Study Section, National Institutes of Health, Public Health Service, Federal Security Agency.
}

is not as rapid as the free periodic acid, there is less danger of hydrolysis with the salt because of the difference in the $\mathrm{pH}$ of the solutions. Chromotropic acid (1, 8 Dihydroxynaphthalene-3, 6-Disulfonic Acid) was selected as the best reagent to determine the liberated formaldehyde (6). Attempts to determine the formaldehyde with this reagent in the presence of the other oxidation products were not satisfactory. As a result, it became necessary to distill the formaldehyde from the reaction solution and then determine the formaldehyde in the distillate by means of the chromotropic acid reagent.

\section{PROCEDURE}

An aqueous solution of the dihydrostreptomycin salt is prepared to give an estimated $20,000 \mu \mathrm{g} / \mathrm{ml}$. A $5-\mathrm{ml}$ aliquot of this solution is transferred to a $50-\mathrm{ml}$ glass stoppered flask and $10 \mathrm{ml}$ of an aqueous $0.05 \mathrm{M}$ sodium metaperiodate solution added. The oxidation is allowed to proceed overnight at room temperature. After oxidation, a 3-ml aliquot is transferred by means of a pipette to the distilling bulb (Figure 1). An excess of sodium thiosulfate (approximately saturated solution) is added to destroy any remaining periodate. The formaldehyde is then distilled by steam while passing a small stream of air through the system to aid the distillation. Approximately $48 \mathrm{ml}$ of distillate is collected in a $50-\mathrm{ml}$ volumetric flask and made to volume with water. A $1-\mathrm{ml}$ aliquot of the distillate is transferred to a $50-\mathrm{ml}$ volumetric flask and $10 \mathrm{ml}$ of concentrated sulfuric acid is slowly added. One $\mathrm{ml}$ of the chromotropic acid reagent (2.5 grams chromotropic acid plus 0.5 gram sodium bisulfite per $100 \mathrm{ml}$ water) is added and the flask is heated in a boiling water bath for 15 minutes. The solution is cooled, distilled water is added with cooling and the solution finally made to $50 \mathrm{ml}$ with distilled water at room temperature. A blank is prepared by adding $1 \mathrm{ml}$ of water, $10 \mathrm{ml}$ of concentrated sulfuric acid, $1 \mathrm{ml}$ of chromotropic acid reagent, heating and making to volume as above. The per cent transmittance of the unknown solution is read in a $1-\mathrm{cm}$ cell in a photoelectric colorimeter, using a $575-\mathrm{m} \mu$ filter and setting the instrument at 100 per cent transmittance for the blank solution.

A standard curve is prepared by oxidizing a standard solution of dihydrostreptomycin, distilling aliquots into separate $50-\mathrm{ml}$ flasks and treating the distillates as indicated above with chromotropic acid. The per cent transmittances obtained on the standard solutions are plotted 
TABLE I

Comparison of chemical and bioassay of commercial samples of dihydrostreptomycin*

\begin{tabular}{c|l|c|c}
\hline \multirow{2}{*}{\begin{tabular}{c|}
$*$ \\
Mfgr.
\end{tabular}} & \multirow{2}{*}{ Type salt } & \multicolumn{2}{|c}{$\begin{array}{c}\text { Grams of dihydrostreptomycin } \\
\text { per vial }\end{array}$} \\
\cline { 3 - 4 } & & Chemical & Bioassay \\
\hline A & Sulfate & 1.10 & 1.11 \\
& Sulfate & 1.10 & 1.04 \\
B & Hydrochloride & 1.10 & .99 \\
& Hydrochloride & 1.12 & 1.12 \\
C & Sulfate & 1.06 & 1.04 \\
& Sulfate & .90 & 1.05 \\
D & Sulfate & 1.06 & 1.03 \\
& Sulfate & 1.05 & 1.08 \\
E & Sulfate & 1.23 & 1.06 \\
& Sulfate & 1.05 & 1.00 \\
\hline
\end{tabular}

* All of the above samples were labeled to contain one gram of dihydrostreptomycin per vial. as the ordinate on semi-log paper against the concentrations in micrograms of the dihydrostreptomycin standard as the abscissa. A straight line relationship is obtained. The per cent transmittance of the unknown is located on the curve and the corresponding concentration of dihydrostreptomycin read off the graph.

Table I shows the values obtained when ten commercial samples were analyzed by this procedure as compared to the turbidimetric bioassay method. The values indicate a good agreement between the two methods. The standard dihydrostreptomycin sulfate ${ }^{2}$ used in this study was a relatively pure sample as determined by chemical and biological assay.

A series of streptomycin samples were analyzed for their dihydrostreptomycin content by this

2 Supplied through the courtesy of Chas. Pfizer \& Co., Inc.

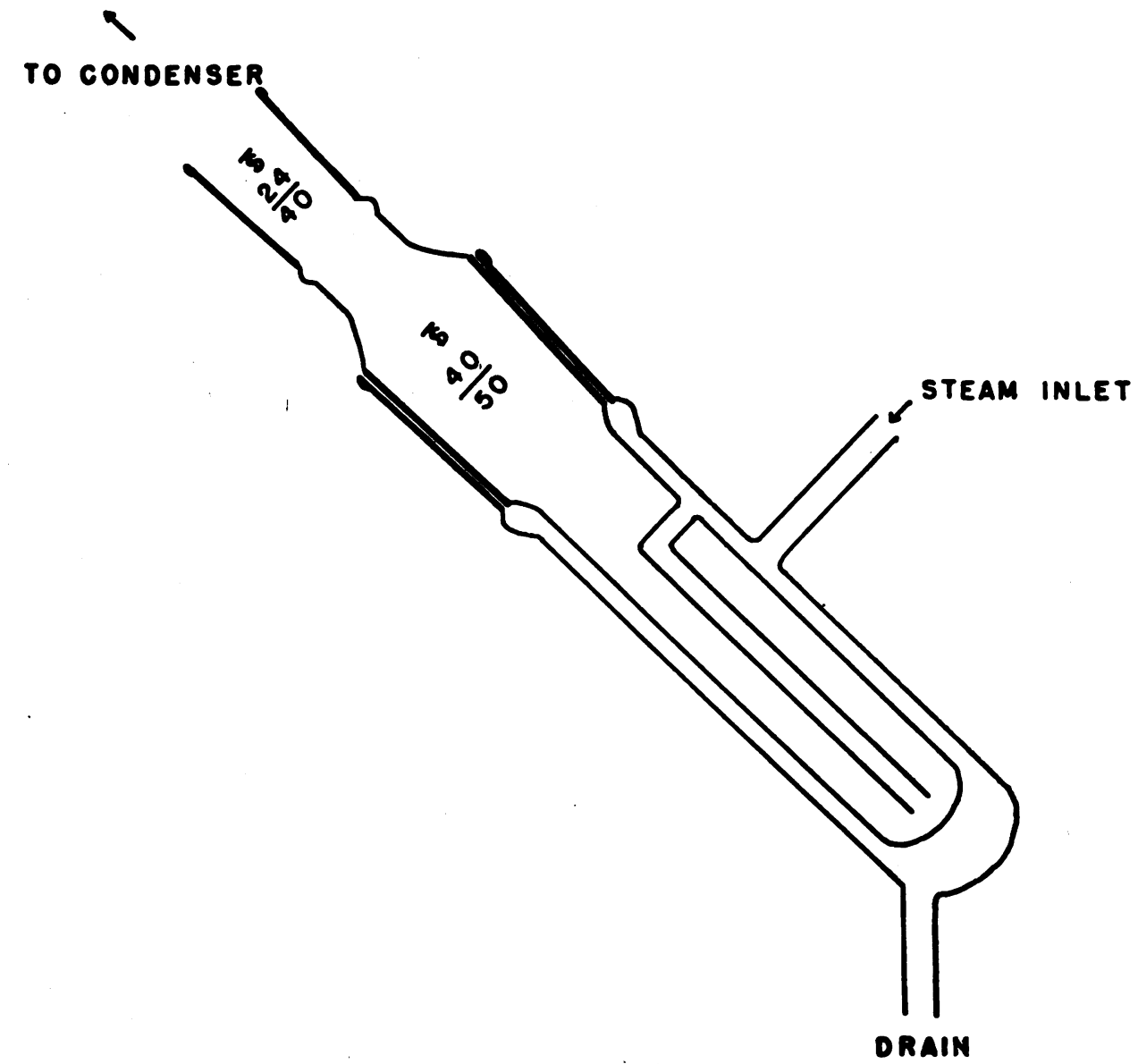

Fig. 1. Distillation Bulb for Distilliting Formaldehyde with Stram 
procedure. Two samples (both from the same manufacturer) showed 10 and 13 per cent dihydrostreptomycin while the others showed less than 6 per cent. It is possible that impurities capable of reacting with periodate to give formaldehyde are responsible for some of the apparent dihydrostreptomycin content of these commercial streptomycin samples. The FDA streptomycin sulfate working standard showed less than 3 per cent dihydrostreptomycin by the above method. A relatively pure sample of streptomycin $\mathrm{B}^{3}$ also showed less than 3 per cent dihydrostreptomycin as determined by this procedure. The data obtained during this study indicate the proposed chemical method is reliable for the analysis of relatively pure dihydrostreptomycin samples.

\section{SUM MARY}

Dihydrostreptomycin may be quantitatively determined by the colorimetric measurement of the formaldehyde liberated after oxidation with periodate.

\section{BIBLIOGRAPHY}

1. Jackson, E. L., Organic Reactions. John Wiley \& Sons, Inc., 1944, New York, Vol. 2, p. 341.

2. 2. Peck, R. L., Hoffhine, C. E., Jr., Peel, E. W., Graber, R. P., Holly, F. W., Mozingo, R., and Folkers, K., Streptomyces antibiotics. VII. The structure of streptidine. J. Am. Chem. Soc., 1946, 68, 776.

b. Brink, N. G., Kuehl, F. A., Jr., Flynn, E. H., and Folkers, K., Streptomyces antibiotics. XI. The structure of tetraacetylbisdesoxystreptobiosamine. Ibid., 1946, 68, 2405.

c. Kuehl, F. A., Jr., Flynn, E. H., Brink, N. G., and Folkers, K., Streptomyces antibiotics. XIII. The structure of streptobiosamine. Ibid., 1946, 68, 2679.

${ }^{8}$ Supplied through the courtesy of Heyden Chemical Corporation. d. Kuehl, F. A., Jr., Peck, R. L., Hoffhine, C. E., Jr., Peel, E. W., and Folkers, K., Streptomyces antibiotics. XIV. The position of the linkage of streptobiosamine to streptidine in streptomycin. Ibid., 1947, 69, 1234.

e. Brink, N. G., Kuehl, F. A., Jr., Flynn, E. H., and Folkers, K., Streptomyces antibiotics. XVI. The structures of bis-desoxystreptose, dihydrodesoxystreptose and tetraacetyl-bis-desoxystreptobiosamine. Ibid., 1948, 70, 2085.

f. Kuehl, F. A., Jr., Peck, R. L., Hoffhine, C. E., Jr., and Folkers, K., Streptomyces antibiotics. XVIII. Structure of streptomycin. Ibid., 1948, 70, 2325.

g. Kuehl, F. A., Jr., Bishop, M. N., Flynn, E. H., and Folkers, K., Streptomyces antibiotics. XIX. Dihydrostreptosonic acid lactone and configuration of streptose and streptobiosamine. Ibid., 1948, 70, 2613.

3. a. Carter, H. E., Clark, R. K., Jr., Dickman, S. R., Loo, Y. H., Meek, J. S., Skell, P. S., Strong, W. A., Alberi, J. I., Bartz, Q. R., Binkley, S. B., Crooks, H. M., Jr., Hooper, I. R., and Rebstock, M. C., Degradation of streptomycin and the structure of streptidine and streptamine. Science, 1946, 103, 53.

b. Fried, J., Boyack, G. A., and Wintersteiner, O., Streptomycin: the chemical nature of streptidine. J. Biol. Chem., 1946, 162, 391.

c. Carter, H. E., Loo, Y. H., and Skell, P. S., Streptomycin: the linkage between streptidine and streptobiosamine. Ibid., 1947, 168, 401.

d. Wolfrom, M. L., and DeWalt, C. W., The configuration of streptose. J. Am. Chem. Soc., 1948, 70, 3148.

e. Wolfrom, M. L., and Polglase, W. J., Degradative studies on streptomycin. Ibid., 1948, 70, 2835.

4. Lemieux, R. U., DeWalt, C. W., and Wolfrom, M. L., Degradative studies on streptomycin. J. Am. Chem. Soc., 1947, 69, 1838.

5. Fried, J., and Stavely, H. E., Abstract of paper presented before the Division of Biological Chemistry of the American Chemical Society at the Chicago meeting in April 1948.

6. Boos, R. N., Quantitative colorimetric microdetermination of methanol with chromotropic acid reagent. Anal. Chem., 1948, 20, 964. 